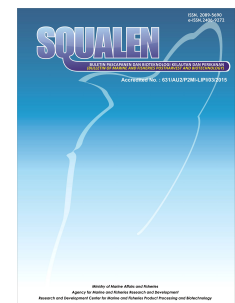

\title{
Detection of rtxA Gene as a Biomarker of Seafood-Borne Pathogen Vibrio cholerae using In Silico PCR Assay
}

Stalis Norma Ethica ${ }^{1 *}$, Nur Hidayati ${ }^{1,2}$, Hayatun Fuad ${ }^{1}$, Chaerul Arham ${ }^{1,3}$, Rivana Ariyadi ${ }^{1,4}$, Ellyka Purwaningrum ${ }^{1,5}$, and Kazi Mohammad Zillur Rahman ${ }^{6}$

${ }^{1}$ Magister Program of Medical Laboratory Science, Universitas Muhammadiyah Semarang, Jl. Kedungmundu Raya No.18, Semarang, Indonesia 50273

${ }^{2}$ Anugerah Pekalongan Hospital, Jl. Perintis Kemerdekaan no. 3, Pekalongan, Indonesia, 51145

${ }^{3}$ Politeknik Kesehatan Muhammadiyah Makassar, Jl. Ratulangi no. 101, Makassar, Indonesia, 90222

${ }^{4}$ Sekolah Tinggi IImu Kesehatan Muhammadiyah Ciamis, Jl. K.H Ahmad Dahlan no. 20, Ciamis, Indonesia, 46216

${ }^{5}$ Medical Faculty, Universitas Wahid Hasyim Semarang, Jl. Kolonel Warsito, Semarang, Indonesia, 50232

${ }^{6}$ Centre for Marine Science and Innovation, University of New South Wales, Level 5 East, Biological Sciences North (D26), Kensington, New South Wales, Australia, 2052

Article history:

Received: 4 March 2020; Revised: 17 July 2020; Accepted: 1 August 2020

\begin{abstract}
Seafood-borne outbreaks caused by Vibrio cholerae have led to the increased need for food safety risk assessment of marine products. An in silico investigation about the potential of virulence gene of $V$. cholerae, $r t x A$, as a DNA biomarker of the toxigenic bacterium has been carried out. The aim of this study was to use the bacterial DNA biomarker sequence as a tool to facilitate early rapid detection of cholera infection. Five specific pairs of primers were designed from the $r t x A$ open reading frame DNA of $V$. cholerae O1 biovar El Tor str. N16961 genomic DNA using Primer3Plus. Next, in silico Polymerase Chain Reaction (PCR) assay was carried out using the newly designed primers and 25 genomic DNA of vibrio spp. retrieved from the in silico database. One of the five designed pairs of primers, RtxAOF-RtxAOR: '5-CGCAAAACAGTTTCAGCCGA-3' and 5'-AGGTTGGTCTTTTGTGGCCA-3', could result in single DNA amplicon sized 518 bp only from $V$. cholerae species. No amplicon bands were produced from 17 other vibrio genomes studied using similar RtxAF-RtxAR primers. A further check showed that the amplicon was indeed part of the $r t x A$ gene of $V$. cholerae. Based on this in silico study, $r t x A$ gene appeared to be a DNA biomarker of $V$. cholerae, which is potential to facilitate rapid diagnosis of the virulence bacterium using in silico PCR assay.
\end{abstract}

Keywords: seafood-borne infection, Vibrio cholerae, DNA biomarker, primer design, rtxA

\section{Introduction}

Seafood products are consumed worldwide, therefore playing a significant role in the economic market (Bonnin-Jusserand et al., 2019). The proportion of globally produced-seafood commodities that is internationally-traded is higher than other products. It is also increasing mostly due to globalization (Guillen et al., 2019). However, several recent outbreaks of human gastroenteritis have been linked to the consumption of contaminated seafood (Elbashir et al., 2018).

Infectious diseases are classified as illnesses caused by pathogenic microorganisms, including bacteria. Such diseases have been the main threat worldwide and have a significant impact on public health and the world's economy (Hwang, Hwang, \& Bueno, 2018). Seafood-borne outbreaks caused by bacterium have led to the increased need for food safety risk assessment of marine products. Continuous monitoring of bacterial contamination in aquatic products and identification of risk factors are, therefore, crucial for assuring food safety $(\mathrm{Xu}, \mathrm{Wu}, \&$ Chen, 2019).

Investigation of seafood-borne illnesses caused by bacteria and viruses requires a concrete knowledge about the pathogenicity and virulence properties of the etiologic agents (Elbashir et al., 2018; Iwamoto, Ayers, Mahon, \& Swerdlow, 2010). Among pathogenic bacteria- contaminating seafood, $V$. cholerae is the

${ }^{*}$ Corresponding author.

E-mail: norma@unimus.ac.id 
main Vibrio species responsible for the dramatic increase of seafood-borne infections worldwide (Bonnin-Jusserand et al., 2019). V. cholerae is notorious as the causal agent of cholera, a severe diarrheal disease, which could be quickly fatal if untreated. It is commonly transmitted via contaminated water and person-to-person contact (Baker-Austin et al., 2018). Approximately 2.9 million cases of cholera and 95,000 deaths had occurred annually worldwide between 2008 and 2012 (Ali, Nelson, Lopez, \& Sack, 2015).

To date, more than 200 serogroups of $V$. cholerae have been recognized, based on variable somatic $\mathrm{O}$ antigen composition; $\mathrm{O} 1$ was the only known epidemic serogroup of $V$. cholerae up to 1991. In 1992, serogroup O139 was identified as the second epidemic serogroup of $V$. cholerae (Albert et al., 1993; Bhattacharya et al., 1993). Within the $V$. cholerae 01 serogroup, there are two well-established biotypes: classical and EI Tor. The EI Tor biotype emerged in 1961 and subsequently displaced the classical biotype as a cause of cholera throughout the world (Pradhan, Baidya, Ghosh, Paul, \& Chowdhury, 2010). Both classical and EI Tor biotypes are differentiated from each other by several properties, including agglutination of chicken red blood cells, susceptibility to polymyxin B and to biotype-specific phages, haemolysis of sheep red blood cells, and Voges-Proskauer reaction (Kaper, Morris Jr, \& Levine, 1995). V. cholerae strains of El Tor biotype initiated the seventh cholera pandemic, which is continuing to cause outbreaks worldwide with catastrophic effects.

Among the critical virulence factors of $V$. cholerae are the cholera toxin (CTX) genetic element and the repeats in toxin (RTX) cluster (Davis, Moyer, Boyd, \& Waldor, 2000). CTX and RTX are the chief virulence gene clusters and are grouped together (Cheng, Zhou, Kan, Wang, \& Rui, 2014). The RTX family of toxins generally produced by several pathogenic Gram-negative bacteria. The RTX toxins constitute a family of dominant virulence factors that have widely spread among Gram-negative bacteria. In $V$. cholerae, the RTX toxin gene cluster encodes the presumptive cytotoxin $(r t \times A)$, an acyltransferase $(r t x C)$, and a related ATP-binding cassette transporter system (two proteins for toxin transportation, RtxB and RtxD) (Chou et al., 2001; Lin et al., 1999)

The search for the ideal biomarkers in infectious diseases with high sensitivity, specificity, and predictive capacity must initially be focused on detection and identification of the infectious agent (Mohan \& Harikrishna, 2015). V. cholerae genomic sequence provides a starting point for understanding how a freeliving, environmental organism emerged to become a significant human bacterial pathogen. The complete genomic sequence of the Gram-negative, gammaProteobacterium V. cholerae El Tor N16961 has been reported to have a length of $4,033,460$ base pairs (bp) (Heidelberg et al., 2000). Numerous mutations, however, have been reported in $V$. cholerae 01 strains encompassing genes, which code virulence factors including the repeat in toxins $(r t \times A)$. In the case of seafood-borne infectious disease, detection and identification of the infectious agent $V$. cholerae are therefore necessary to do. In this study, $r t x A$, a member of RTX chief virulence gene cluster, was tested for its potential as a DNA biomarker of $V$. cholerae. Such biomarker is beneficial to facilitate early rapid diagnosis of $V$. cholerae infection using in vitro PCR.

\section{Material and Methods}

A literature study was initially conducted to obtain information related to the unique phenotypic feature of $V$. cholerae, particularly on specific toxins the species produces. Next, the genotype feature, such as genes associated with proteins underlining the unique phenotype was targeted. Primers were then designed from the internal part of open reading frame (ORF) of the targeted gene sequences in FASTA format as input using Primer3Plus at https://primer3plus.com/ (Untergasser et al., 2007; Ethica et al., 2013; Ethica, 2014; Ethica, Sulistyaningtyas, \& Darmawati, 2019; Ethica, Darmawati, Dewi, Nurrahman, \& Sulistyaningtyas, 2020). The input of the program is basically a FASTA format of a gene of interest. Pairs of primers having the least possibility of hairpin formation, self-complementarity, and dimerization were selected (Ethica, Semiarti, Widada, Oedjijono, \& Raharjo, 2017). The newly designed primers were subsequently used as input for the web-based in silico PCR. The virtual PCR work was run from a web-based software at http://insilico.ehu.es/PCR/ using Vibrio spp. genomes stored in the program database. In silico PCR can be done by choosing "PCR Amplification" from the main page of the website, and once it opens, inserts the primers, then click "amplify" (Bikandi, Millán, Rementeria, \& Garaizar, 2004; San Millán, Martínez-Ballesteros, Rementeria, Garaizar, \& Bikandi, 2013); Ethica, Sulistyaningtyas, \& Darmawati, 2019; Ethica, Darmawati, Dewi, Nurrahman, \& Sulistyaningtyas, 2020). The nucleotide database used in the in silico PCR website comes from National Center of Bioinformatics Institute (NCBI) database. An analysis was eventually carried out to confirm if the in silico PCR products (amplicons) were specific to $V$. cholerae species and were indeed part of genes targeted as DNA biomarkers. This analysis is conducted to check whether the in silico PCR amplicons virtually seen on gel electrophoresis were correct according to primer positions. The analysis 
was carried out by "clicking" the amplicon band or size shown by the in silico PCR result window.

\section{Results and Discussion}

Severe infection outbreaks originated from fish and other foods often create a diagnostic challenge for clinicians. There is a limited official guidance to help clinicians decide which biomarkers that can aid with the diagnosis of bacterial infections (Rogers et al., 2011). Therefore, the development of bacterial DNA biomarkers to detect $V$. cholerae was carried out in this study. It was expected that in the case of diarrheal infection outbreaks, the involvement of $V$. cholerae could be determined by detecting the presence of their DNA biomarkers.

From a literature study, it is known that $r t x A$ gene, a member of RTX gene cluster, is among distinct genotypic features of infectious bacterium $V$. cholerae (Lin et al., 1999). The uniqueness of the gene makes it potential to be targeted as a DNA biomarker of $V$. cholerae species. The $r t x A$ gene sequence was then retrieved from the genome sequence of $V$. cholerae
O1 biovar El Tor strain N16961 (NCBI Reference Sequence: NC_002505.1). The sequence encodes RTX toxin RtXA [Vibrio cholerae O1 biovar El Tor str. N16961 in the NCBI GenBank] (NCBI Reference Sequence: NP_231094.1). The 3-D structure of cholera RtxA protein (UniProt accession number: Q9KS12) as the product of $r t x A$ gene is shown in Figure 1. Using primer3Plus (Untergasser et al., 2007), pairs of primers obtained by using rtxA DNA sequence as input (Figure 1) are listed in Table 1.

In silico PCR assay using Pair 2 primers and genomic DNA of 25 Vibrio species were run on http:/ /insilico.ehu.es/PCR/. The assay resulted in eight single 518-bp DNA bands (Figure 2) belonging to all $V$. cholerae or species number 4 to 11 (Table 2, highlighted). According to Table 2, V. cholerae species number 4-11 are V. cholerae, V. cholerae str. IEC224, V. cholerae str. LMA3984-4, V. cholerae str. M66-2, V. cholerae str. MJ-1236, V. cholerae O1 str. 2010EL1786, V. cholerae str. O395, and V. cholerae str. O395 chromosome 1. Table 1 shows that though primers were designed from similar $r t x A$ sequence, not all primers could detect unique conserved regions of $r t x A$

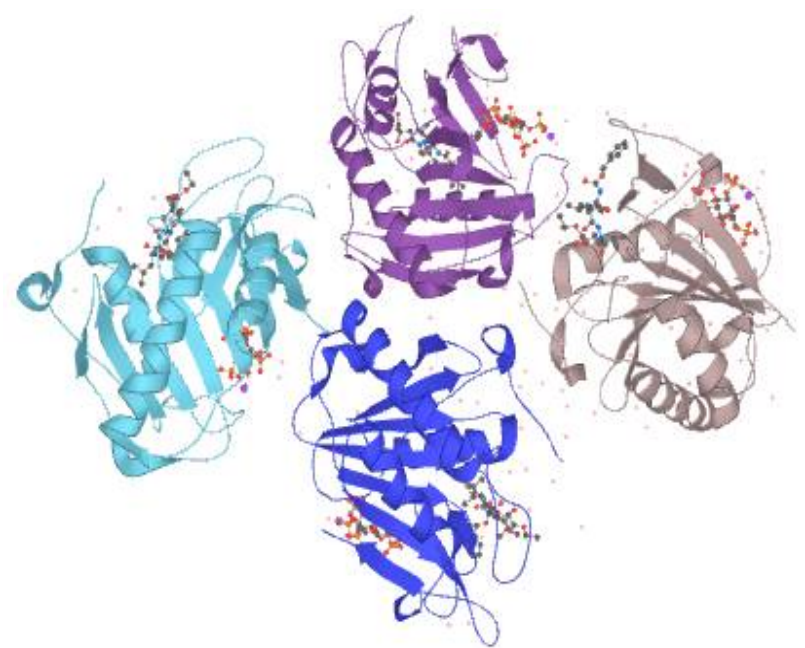

Figure 1. The 3-D structure of cholera RtxA protein ( $r$ txA gene product) visualized by Litemol (UniProt Accession Number: Q9KS12)

Table 1. Primers designed using Primer3Plus from $r t x A$ DNA sequence

\begin{tabular}{ccccc}
\hline Primer & Forward Primer & Reverse Primer & $\begin{array}{c}\text { Amplicon } \\
\text { Size (bp) }\end{array}$ & $\begin{array}{c}\text { DNA of } \boldsymbol{V} \text {. cholerae } \\
\text { strains amplified } \\
\text { (genome code number) }\end{array}$ \\
\hline Pair 1 & GCGCGAACGTAATAACCCAC & ACCGACATGCCATCACCAAT & 508 & 4,5 , and 7-9 \\
Pair 2 & CGCAAAACAGTTCAGCCGA & AGGTTGGTCTTTGTGGCCA & 518 & $4-11$ (all V. cholerae) \\
Pair 3 & GTGGCGCGAACGTAATAACC & AGATGTTGACGTTCCCCACC & 597 & 4,5 , and 7-9 \\
Pair 4 & TAGCGGTGAAAGCTCAGGTG & GTTATTACGTTCGCGCCACC & 585 & 4,5 , and 7-9 \\
Pair 5 & GCGCATTTACTGGCTTACGG & TGGTGAAGATGTACCCGCC & 559 & $4-9$ \\
\hline
\end{tabular}


of all strains of $V$. cholerae, which differentiate them from other Vibrio species (genome code number 1-3 and 12-25, see Table 2). Also, not all of these primers could detect all $V$. cholerae strains. Only Pair 2 primer that could indicate $r t x A$ conserved regions of all $V$. cholerae strains. As seen in Table 1, Primer3Plus by default produces five best pairs of primers a output and automatically eliminates low quality primers that have the potential of mispriming, self-dimer, or cross dimer.

After carrying out the in silico PCR assay, it is necessary to check whether the amplicon products that where seen on the virtual gel electrophoresis
(Figure 2) were correct, based on the primer positions. The analysis was carried out easily by clicking the amplicon size that appeared on the in silico PCR result window. A new tab was then appeared, showing that the in silico amplicons were indeed part of the $\operatorname{rt} x A$ gene fragments (Figure 3 ). The DNA sequence seen in Figure 3 represents one of eight PCR amplicon run on in silico PCR using the selected Pair 2 primer (see Table 1) and a genome of vibrios (species number 4 , see Table 2).

"Clicking" step on the amplicon size on in silico PCR (Figure 2) was necessary. The result is shown in Figure 3. This is a way to prove that even though

Table 2. List of genomic DNA of Vibrio spp. used as in silico PCR templates

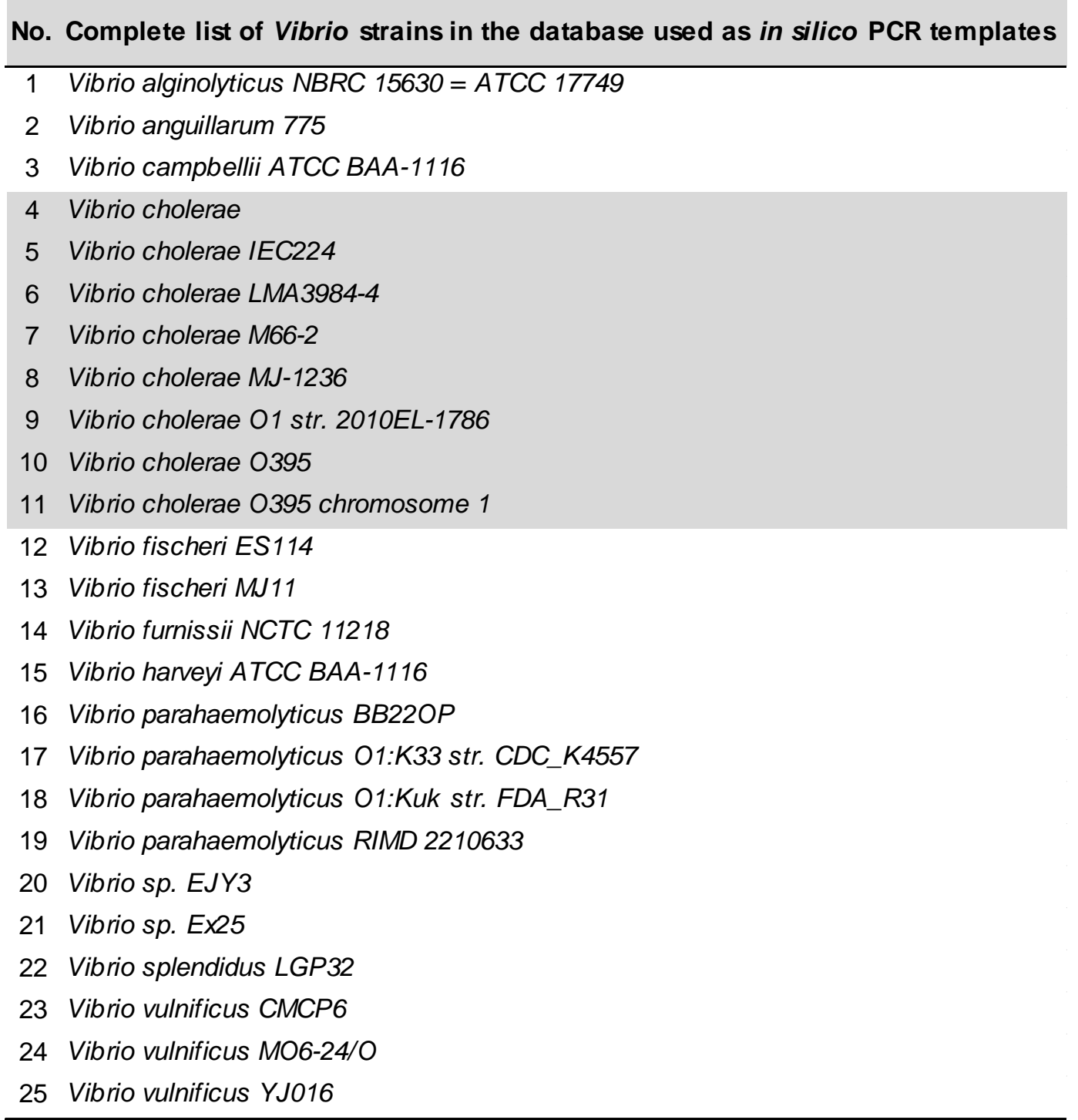

Note: Highlighted rows are genomic sequences of Vibrio cholerae strains among those of other Vibrios (25 strains) available that were retrieved from the in silico database at the time of this study. 


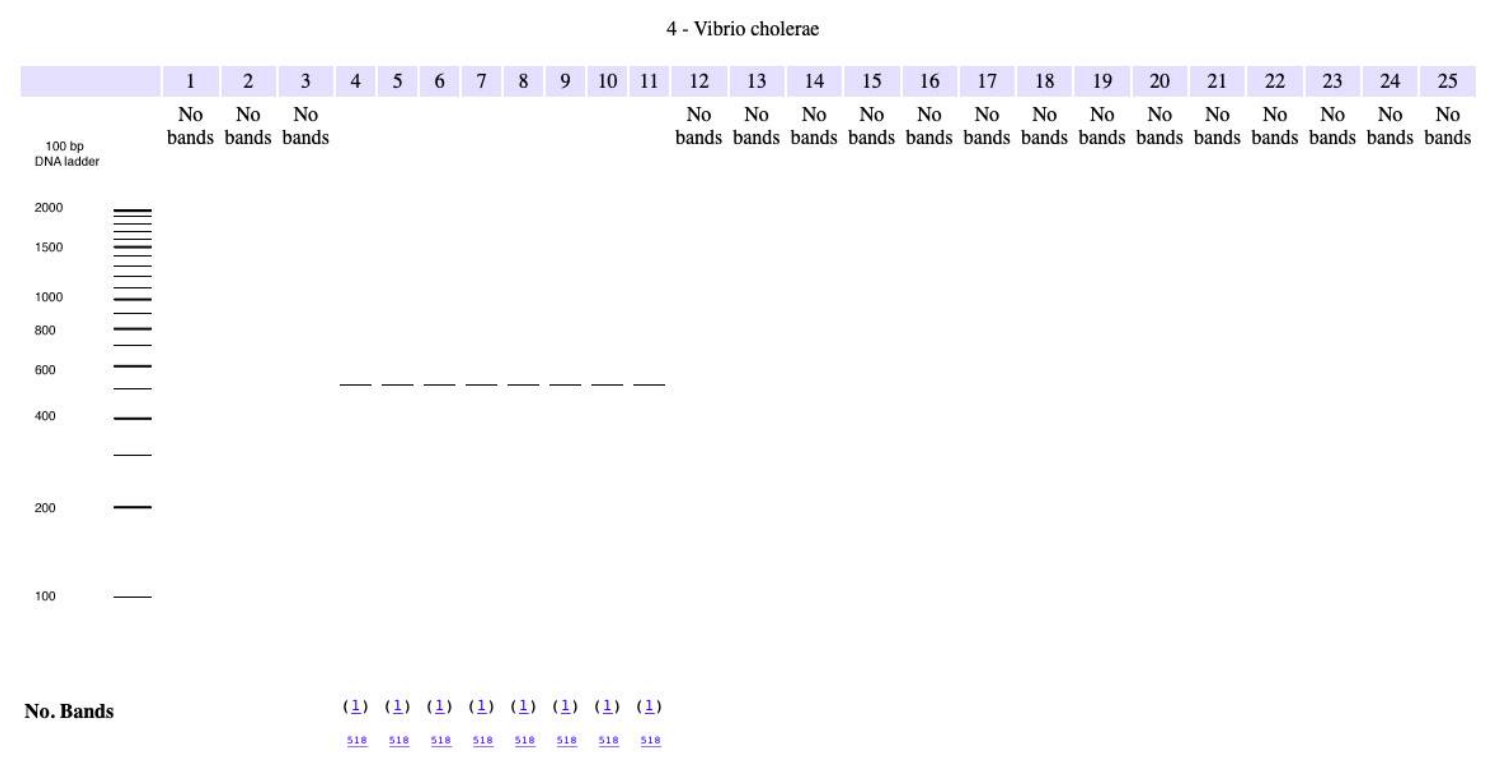

Figure 2. In silico PCR assay using Pair 2 primer and 25 Vibrio genomic DNA resulted seven single 518-bp DNA bands belonging to all $V$. cholerae strains

\author{
Genome: Vibrio cholerae \\ Start position: 1558124 \\ End position: 1558641 \\ Length: 518
}

\title{
DNA sequence
}

\begin{tabular}{l} 
>NC_002505, from 1558124 to 1558641 (518 bp); Vibrio cholerae \\
CGCAAAACAGTTTCAGCCGACTATATGACCAGCTAGAAGCCGCTAACTTGAAAGAGAGTAAGCACCTTTA \\
TCTGGATCAAAATGGTGACTTTGTTACCAAAGGCAAAGGTAATCTTGCCAATATCGATCTGCTAGGTAGC \\
CGCGAAGCTGTGCTTGAAAAAGTGAAGTTAACAGTAAGTAACGAGTACGGTCAAACCGTTGCGGATACAA \\
TTTTTGCTGGATTATCAGCCAAAGATCTTGCCAAAGACGGTAAAGGGGTGATATCGCGGGTTGAATAA \\
AGTACATCAAGCGATTGAACAGCATCTGTCACCTGTCAGCGCCACGTTGACATTTGGAACCGAGTGAT \\
CATAGCGCGCTAGGTCATGCCGCATTGCAAATAGGCCAAGGTCGCACGCAACTTGAAGGTCAAGCTGCAG \\
CTGATTTAACCAGCAAAATTACGTAAGCTGGTGGCCACTAGGCAGCAAGTCATCCAATATCAGCAATAT \\
CTTGAATGTGGCCACAAAAGACCAACCT \\
Translate to protein \\
$\underline{\text { Restriction digest }}$ \\
BLAST \\
Design primers with primer 3 \\
\hline
\end{tabular}

\section{Gene(s) or part of gene(s) amplified:}

ORF. 1550108-1563784 Sequence VC1451 - RTX toxin RtxA

Figure 3. In silico PCR amplicon with V. cholerae genome sequence as the template using Pair 2 primer designed in this study

Vibrio spp. might have the same $r t x A$ gene, our primers recognize specific DNA regions, which is part of $r t x A$ of $V$. cholerae only, and not part of $r t x A$ of other Vibrio species. Primer sequences used in this study were taken from the $r t x A$ gene of $V$. cholerae precisely because we targeted all strains of this species. Not all primers designed from the $r t x A$ gene could amplify the targeted genome selectively and therefore the in silico PCR was conducted. In this case, checking the amplicon size was carried out to confirm if the amplicon was the genuine part of $r t x A$. Occasionally, in silico PCR resulted DNA amplicon, which is not the targeted gene. This step also confirmed that primers, other than Pair 2, that were designed from 


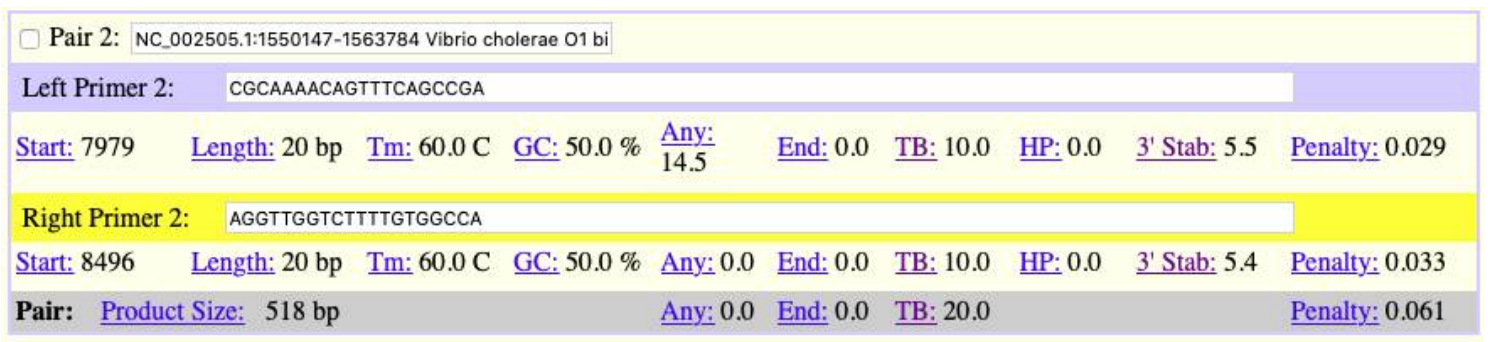

Send to Primer3Manager Reset Form

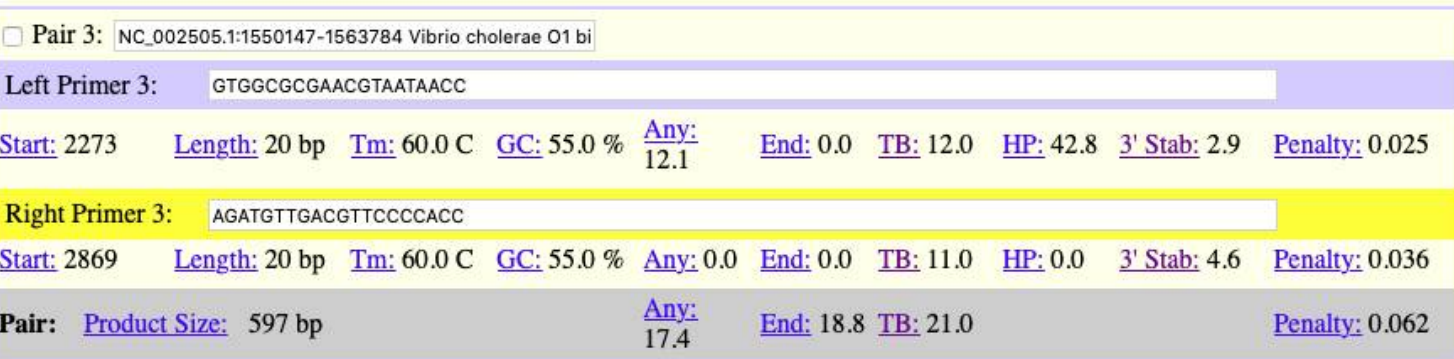

Figure 4. The output of Primer3Plus showing complete parameters of Pair 2 Primer, including HP (hairpin possibility)

the targeted $r t x A$ gene of a $V$. cholerae could produce positive in silico PCR bands using all of its strains' genome (in this study eight strains).

Primers designed to amplify the $r t x A$ gene of $V$. cholerae have been reported before. According to the previous report, a pair of designed primers, rtxA-F 5'GGGATACAATGCCCTCTGGCA-3' and rtxA-R 5'TGGGTTGGCGGTTGGATTTTAC-3', was successfully used to detect $r t x A$ of $V$. cholerae (Xu et al., 2019; Rivera, Chun, Huq, Sack, \& Colwell, 2001). Despite being able to amplify the targeted genes in most $V$. cholerae strains by showing $977 \mathrm{bp}$ amplicon, the primers were failed to amplify that of $V$. cholerae strain LMA 3984-4. If a pair of primers theoretically failed to amplify a targeted DNA sequence in an in silico PCR, then they were most likely unable to amplify the same sequence in an in vitro PCR.

In this study, the potential of $r t x A$ gene as a DNA biomarker for $V$. cholerae was tested by conducting in silico PCR assay. To prove the hypothesis, five pairs of primers were successfully designed using webbased Primer3Plus software using $r t x A$ full-length gene sequence of $V$. cholerae O1 biovar El Tor str. N16961. Among five pairs of primers obtained, a new pair of primers (Pair 2 based on Table 1) namely RtXAOFRtXAOR: '5-CGCAAAACAGTTTCAGCCGA-3' and 5'AGGTTGGTCTTTTGTGGCCA-3' passed the hairpin and other stability test results based on Primer3Plus output as seen in Figure 4. In addition, the selected newly designed specific primer, the RtxAOF-RtxAOR, was able to selectively amplify the internal part of the $r t x A$ gene fragments of all genomic sequences of $V$. cholerae, but not those of other Vibrios. It is important to also underline that the in silico PCR assay developed in this study for $r t x A$ could identify $r t x A$ producing $V$. cholerae strains, not only from the $\mathrm{O} 1$, but also the non-O1 serogroup.

Our results infer that the $r t x A$ gene fragment of $V$. cholerae flanked by a pair of primers designed in this study that indicated sequences between QNSFSR and ATKDQPD conserved regions of protein sequences coded by the gene appeared as the biomarker of the bacterium. The $r t x A$ gene fragment could differentiate the infectious bacterial species from other Vibrios.

The newly designed RtxAOF-RtxAOR (Pair 2 primer resulted from primer design work of Primer3Plus) is potential to be used as prospective primers to detect the presence of $V$. cholerae in bacterial samples using in vitro PCR.

Among limitation of this work is that the performance of the obtained primers is only on a theoretical basis, which means the results are predictive. Visual PCR simulation in this study also only utilized resources accessed from http:// insilico.ehu.es/PCR. If an update on the genomic sequence in this study is released, results might slightly change due to the alterations on DNA 
templates used for in silico PCR. Therefore, if a new genomic DNA sequence of $V$. cholerae strain is added on the database, then consequently new in silico PCR assay should be conducted. The aim is to check if the selectivity level of these primers stays the same. Moreover, results from this study could be more meaningful if they are applied for an in vivo PCR study. Thus, they could support early detection and identification to control $V$. cholerae as cholera infection agent directly from actual samples.

\section{Conclusion}

Based on in silico PCR assay carried out in this study, the $r t x A$ gene was theoretically proved to be a DNA biomarker of the seafood-borne pathogenic bacterium $V$. cholerae. The aforementioned gene could be used to differentiate it from other Vibrio species. The newly designed primers are potential to facilitate early rapid diagnosis of cholera infection.

\section{References}

Albert, M. J., Ansaruzzaman, M., Bardhan, P. K., Faruque, A. S. G., Faruque, S. M., Islam, M. S., ... \& Yunus, M. D. (1993). Large epidemic of cholerae-like disease in Bangladesh caused by Vibrio cholerae 0139 synonym Bengal. Lancet, 342(8868), 387-90. doi: 10.1016/0140-6736(93)92811-7.

Ali, M., Nelson, A. R., Lopez, A. L., \& Sack, D. A. (2015). Updated global burden of cholera in endemic countries. PLoS Neglected Tropical Diseases, 9(6), e0003832. doi: 10.1371/journal.pntd.0003832.

Baker-Austin, C., Oliver, J. D., Alam, M., Ali, A., Waldor, M. K., Qadri, F., \& Martinez-Urtaza, J. (2018). Vibrio spp. infections. Nature Reviews Disease Primers, 4(1), 119. doi: 10.1038/s41572-018-0005-8.

Bhattacharya, M. K., Bhattacharya, S. K., Garg, S., Saha, P., Dutta, D., Nair, G. B., ... \& Sack, R. B. (1993). Outbreak of Vibrio cholerae non-01 in India and Bangladesh. Lancet, 341(8856), 1346-1347. doi: 10.1016/0140-6736(93)90855-B.

Bikandi, J., Millán, R. S., Rementeria, A., \& Garaizar, J. (2004). In silico analysis of complete bacterial genomes: PCR, AFLP-PCR and endonuclease restriction. Bioinformatics, 20(5), 798-799. doi: 10.1093/bioinformatics/btg491.

Bonnin-Jusserand, M., Copin, S., Le Bris, C., Brauge, T., Gay, M., Brisabois, A., ... \& Midelet-Bourdin, G. (2019). Vibrio species involved in seafood-borne outbreaks (Vibrio cholerae, V. parahaemolyticus and $V$. vulnificus): Review of microbiological versus recent molecular detection methods in seafood products. Critical Reviews in Food Science and Nutrition, 59(4), 597-610. doi: 10.1080/10408398. 2017.1384715.

Cheng, C., Zhou, Y., Kan, B., Wang, Q., \& Rui, Y. (2014). Construction and characterization of a Vibrio cholerae serogroup 0139 vaccine candidate by genetic engineering. Molecular Medicine Reports, 9(6), 2239-2244. doi: $10.3892 / \mathrm{mmr}$. 2014.2065.

Chow, K. H., Ng, T. K., Yuen, K. Y., \& Yam, W. C. (2001). Detection of RTX toxin gene in Vibrio cholerae by PCR. Journal of Clinical Microbiology, 39(7), 25942597. doi: 10.1128/JCM.39.7.2594-2597.2001.

Davis, B. M., Moyer, K. E., Boyd, E. F., \& Waldor, M. K. (2000). CTX prophages in classical biotype Vibrio cholerae: functional phage genes but dysfunctional phage genomes. Journal of Bacteriology, 182(24), 6992-6998. doi: 10.1128/JB.182.24.6992-6998.2000.

Elbashir, S., Parveen, S., Schwarz, J., Rippen, T., Jahncke, M., \& DePaola, A. (2018). Seafood pathogens and information on antimicrobial resistance: A review. Food Microbiology, 70, 85-93. doi: 10.1016/ j.fm.2017.09.011.

Ethica, S. N. (2014). Detection of genes involved in glycerol metabolism of Alcaligenes sp. JG3 (Doctoral dissertation, Universitas Gadjah Mada). Retrieved from https://repository.ugm.ac.id/id/eprint/126377.

Ethica, S. N., Hammi, M. K., Lestari, P., Semiarti, E., Widada, J., \& Raharjo, T. J. (2013). Amplification of Azospirillum sp. JG3 glpd gene fragment using degenerate primers generated by web-based tools. Journal of Microbiology, Biotechnology and Food Sciences, 3(3), 231.

Ethica, S. N., Semiarti, E., Widada, J., Oedjijono, O., \& Raharjo, T. J. (2017). Characterization of moaC and a nontarget gene fragments of food borne pathogen Alcaligenes sp. JG3 using degenerate colony and arbitrary PCRs. Journal of Food Safety, 37(4), e12345. doi: 10.1111/jfs.12345.

Ethica, S. N., Sulistyaningtyas, A. R., \& Darmawati, S. (2019). In silico specificity comparison between GMFGMR and JMF-JMR primers for detecting moaC genes of food spoilage bacteria Pseudomonas spp. In IOP Conference Series: Earth and Environmental Science, 292(1), 012033. IOP Publishing. doi: 10.1088/1755-1315/292/1/012033.

Ethica, S. N., Darmawati, S., Dewi, S. S., Nurrahman, N., \& Sulistyaningtyas, A. R. (2020). Streptolysin encoding genes sagC and sagD as biomarkers of fish pathogen Streptococcus iniae: an in silico study. Squalen Bulletin of Marine and Fisheries Postharvest and Biotechnology, 15(1), 31-39. doi: 10.15578/ squalen.v15i1.416.

Guillen, J., Natale, F., Carvalho, N., Casey, J., Hofherr, J., Druon, J. N., ... \& Martinsohn, J. T. (2019). Global seafood consumption footprint. Ambio, 48(2), 111122. doi:10.1007/s13280-018-1060-9.

Heidelberg, J. F., Eisen, J. A., Nelson, W. C., Clayton, R. A., Gwinn, M. L., Dodson, R. J., ... \& Gill, S. R. (2000). DNA sequence of both chromosomes of the cholerae pathogen Vibrio cholerae. Nature, 406(6795), 477483. doi: $10.1038 / 35020000$.

Hwang, H., Hwang, B. Y., \& Bueno, J. (2018). Biomarkers in infectious diseases. Disease Markers, 8509127. doi: $10.1155 / 2018 / 8509127$. 
Iwamoto, M., Ayers, T., Mahon, B. E., \& Swerdlow, D. L. (2010). Epidemiology of seafood-associated infections in the United States. Clinical Microbiology Reviews, 23(2), 399-411. doi: 10.1128/CMR.0005909.

Kaper, J. B., Morris Jr, J. G., \& Levine, M. M. (1995). Cholerae. Clinical Microbiology Reviews, 8(1), 48-86. doi: 10.1128/CMR.8.1.48.

Lin, W., Fullner, K. J., Clayton, R., Sexton, J. A., Rogers, M B., Calia, K. E., ... \& Mekalanos, J. J. (1999). Identification of a Vibrio cholerae RTX toxin gene cluster that is tightly linked to the cholerae toxin prophage. Proceedings of the National Academy of Sciences, 96(3), 1071-1076. doi: 10.1073/pnas.96. 3.1071.

Mohan, A., \& Harikrishna, J. (2015). Biomarkers for the diagnosis of bacterial infections: in pursuit of the 'Holy Grail'. Indian Journal of Medical Research, 141(3), 271-273. doi: 10.4103/0971-5916.156551.

Pradhan, S., Baidya, A. K., Ghosh, A., Paul, K., \& Chowdhury, R. (2010). The El Tor biotype of Vibrio cholerae exhibits a growth advantage in the stationary phase in mixed cultures with the classical biotype. Journal of Bacteriology, 192(4), 955-963. doi: 10.1128/JB.01180-09.

Rivera, I. N., Chun, J., Huq, A., Sack, R. B., \& Colwell, R. R. (2001). Genotypes associated with virulence in environmental isolates of Vibrio cholerae. Applied and Environmental Microbiology, 67(6), 2421-2429. doi: 10.1128/AEM.67.6.2421-2429.2001.

Rogers, G. B., Hoffman, L. R., Johnson, M. W., MayerHamblett, N., Schwarze, J., Carroll, M. P., \& Bruce, K. D. (2011). Using bacterial biomarkers to identify early indicators of cystic fibrosis pulmonary exacerbation onset. Expert Review of Molecular Diagnostics, 11(2), 197-206. doi: 10.1586/erm.10.117.

San Millán, R. M., Martínez-Ballesteros, I., Rementeria, A., Garaizar, J., \& Bikandi, J. (2013). Online exercise for the design and simulation of PCR and PCR-RFLP experiments. BMC Research Notes, 6(1), 513. doi: 10.1186/1756-0500-6-513.

Untergasser, A., Nijveen, H., Rao, X., Bisseling, T., Geurts, R., \& Leunissen, J. A. (2007). Primer3Plus, an enhanced web interface to Primer3. Nucleic Acids Research, 35(suppl_2), W71-W74. doi: 10.1093/nar/ gkm306.

Xu, M., Wu, J., \& Chen, L. (2019). Virulence, antimicrobial and heavy metal tolerance, and genetic diversity of Vibrio cholerae recovered from commonly consumed freshwater fish. Environmental Science and Pollution Research, 26(26), 27338-27352. doi: 10.1007/ s11356-019-05287-8. 